\title{
Corticofugal Control of Vibrissa-Sensitive Neurons in the Interpolaris Nucleus of the Trigeminal Complex
}

\author{
Takahiro Furuta, ${ }^{1}$ Nadia Urbain, ${ }^{2}$ Takeshi Kaneko, ${ }^{1}$ and Martin Deschênes ${ }^{2}$ \\ ${ }^{1}$ Department of Morphological Brain Science, Graduate School of Medicine, Kyoto University, Kyoto 606-8501, Japan, and ${ }^{2}$ Centre de Recherche Université \\ Laval Robert-Giffard, Québec City, Québec G1J 2G3, Canada
}

Trigeminal sensory nuclei that give rise to ascending pathways of vibrissal information are heavily linked by intersubnuclear connections. This is the case, for instance, of the principal trigeminal nucleus, which receives strong inhibitory input from the caudal sector of the interpolaris subnucleus. Because this inhibitory input can gate the relay of sensory messages through the lemniscal pathway, a central issue in vibrissal physiology is how brain regions that project to the interpolaris control the activity of inhibitory cells. In the present study, we examined how corticotrigeminal neurons of the primary and second somatosensory cortical areas control the excitability of interpolaris cells. Results show that these two cortical areas exert a differential control over the excitability of projection cells and intersubnuclear interneurons, and that this control also involves the recruitment of inhibitory cells in the caudalis subnucleus. These results provide a basic circuitry for a mechanism of disinhibition through which the cerebral cortex can control the relay of sensory messages in the lemniscal pathway. It is proposed that top-down control of brainstem circuits is prompted by motor strategies, expectations, and motivational states of the animal.

\section{Introduction}

Trigeminal sensory nuclei are the first processing stage of vibrissal information in rodents. They feature distinct populations of thalamic projecting cells and a rich network of intersubnuclear connections (Jacquin et al., 1990a; Furuta et al., 2008), so that what is conveyed to the cortex by each of the ascending pathways depends on local transactions that occur in brainstem. This is the case, for instance, of the principal trigeminal nucleus (PrV) that gives rise to the lemniscal pathway and receives inhibitory projection from the caudal sector of the interpolaris subnucleus (SpVic) (Furuta et al., 2008).

The interpolaris subnucleus $(\mathrm{SpVi})$ of rodents contains two broad classes of cells: large multiwhisker cells that project to the thalamus, superior colliculus, or cerebellum, and small-sized monowhisker cells whose axon arborizes locally in the SpVi and also subserves intersubnuclear connections (Jacquin et al., 1989a,b). Monowhisker cells are particularly abundant in the caudal sector of the nucleus, where the vast majority of neurons express the transcript for the vesicular transporter of GABA and glycine (Furuta et al., 2008). In accord with the anatomical data, lesion of the SpVi was shown to suppress nearly completely surround-whisker inhibition in PrV (Furuta et al., 2008), and it was recently shown that inactivation of the SpVi reduces the inhibitory gating of vibrissal input during free whisking in behaving rats (Lee et al., 2008). These results thus raise the possibility that,

Received Aug. 28, 2009; revised Nov. 13, 2009; accepted Dec. 14, 2009.

This work was supported by Takeda Science Foundation, by Ministry of Education, Science, Sports, and Culture of Japan Grant 20700316 (T.F.), and by Canadian Institutes of Health Research Grant MT-5877 (M.D.).

Correspondence should be addressed to Martin Deschênes at the above address. E-mail: martin. deschenes@crulrg.ulaval.ca.

DOI:10.1523/JNEUROSCI.4274-09.2010

Copyright $\odot 2010$ the authors $\quad 0270-6474 / 10 / 301832-07 \$ 15.00 / 0$ by controlling the activity of intersubnuclear projecting cells, brain regions that project to the $\mathrm{SpVi}$ may take an active part in shaping vibrissal information that is conveyed through the lemniscal pathway.

When retrograde tracers are injected into the SpVi of rodents, the vast majority of retrogradely labeled cells in the brain are found in the other trigeminal nuclei (Jacquin et al., 1990a), in the primary and second somatosensory cortical areas (S1 and S2) (Wise and Jones, 1977; Wise et al., 1979; Killackey et al., 1989), and in the pedunculo-pontine nucleus (Timofeeva et al., 2005). The way these central inputs affect the activity of intersubnuclear-projecting cells is currently unknown, but available evidence suggests that they can exert a decisive influence on the way projection cells respond to vibrissal inputs (Woolston et al., 1983; Hallas and Jacquin, 1990; Jacquin et al., 1990b; Timofeeva et al., 2005). Here, we examined how corticofugal neurons in S1 and S2 modulate the activity of interpolaris cells. Results show that these cortical areas exert a differential control over the excitability of projection cells and intersubnuclear interneurons and that this control also involves the recruitment of inhibitory cells in the caudalis subnucleus. These results provide direct evidence for a top-down control of information processing that operates at the very first relay station of the vibrissal system.

\section{Materials and Methods}

Animal preparation and recordings. Experiments were performed in 27 male rats (Sprague Dawley; 250-300 g) in accordance with federally prescribed animal care and use guidelines. The Ethical Committee for Animal Use in Research (Laval University) and the Institute of Laboratory Animals, Graduate School of Medicine (Kyoto University) approved all experimental protocols.

Electrophysiological experiments were conducted under ketamine ( 75 $\mathrm{mg} / \mathrm{kg}) /$ xylazine $(5 \mathrm{mg} / \mathrm{kg}$ ) anesthesia. The left facial nerve was cut, and 
the animal was placed in a stereotaxic apparatus. The animal breathed freely, and body temperature was maintained at $37.5^{\circ} \mathrm{C}$ with a heating pad controlled thermostatically. Throughout the experiment, a deep level of anesthesia was maintained (stage III-3) (Friedberg et al., 1999) by additional doses of anesthetics $(20 \mathrm{mg} / \mathrm{kg}$ ketamine plus $0.3 \mathrm{mg} / \mathrm{kg}$ xylazine, i.m.) given as needed to abolish reflex to sharp pinch of the hindlimbs.

Single interpolaris cells were recorded extracellularly with glass micropipettes $(1 \mu \mathrm{m})$ filled with a solution of potassium acetate $(0.5 \mathrm{M})$. Micropipettes were lowered vertically through the cerebellum at frontal planes 12-13.5 mm behind the bregma (Paxinos and Watson, 1998). Signals were amplified, bandpass filtered $(150 \mathrm{~Hz}$ to $3 \mathrm{kHz})$, sampled at $10 \mathrm{kHz}$, and stored on hard disk for off-line analysis.

Whisker and cortical stimulation. Vibrissae were cut $\sim 1 \mathrm{~cm}$ from the skin, and the whiskers that compose the receptive field of a cell were identified by manual deflection under a dissecting microscope. An audio monitor and a computer display were used to monitor the responses. In some cases, especially when a cell responded to two to three whiskers, a piezoelectric stimulator was used to ensure that responses did not result from mechanical motion through the vibrissal pad.

A barrel column, usually D2 or D3, was identified by averaging field potential and multiunit activity evoked in layer 4 (depth, $740 \mu \mathrm{m}$ below the pia) after separate deflection of the corresponding whisker and surrounding whiskers with a piezoelectric stimulator. Recordings were performed with a micropipette (tip size, $4 \mu \mathrm{m}$ ) filled with a solution of $\mathrm{NaCl}$ $(0.5 \mathrm{M})$. Usually three to four penetrations were made to find the site at which the selected whisker elicited the largest response (presumably the center of a barrel). Then, a pair of glass-insulated platinum/iridium microelectrodes (tip size, $5 \mu \mathrm{m} ; 800 \mathrm{k} \Omega$; FHC) was lowered at the same site in that barrel column. The tips of microelectrodes were spaced vertically by $1.2 \mathrm{~mm}$ and laterally by $150 \mu \mathrm{m}$. Thus, with the deeper electrode inserted into layer 5 ( $1.5 \mathrm{~mm}$ below the pia), the upper one was in the overlying layers $2-3$. This bipolar configuration contributed to restrict current spread to a single barrel column, and corticotrigeminal excitatory responses were typically evoked at low current intensity (three pulses; pulse duration, $200 \mu$ s; frequency, $330 \mathrm{~Hz}$; intensity, $15-50 \mu \mathrm{A}$; intertrain interval, $1.2 \mathrm{~s}$ ). Although some of the units were tested with higher current intensities (up to $200 \mu \mathrm{A}$ ), these results are not included in the present report because of the risk of current spread to neighboring barrels and septa.

Stimulation of the deep layers of the motor and S2 cortices (depth, 1.5 $\mathrm{mm}$ ) was performed with a pair of platinum/iridium microelectrodes with tips $1 \mathrm{~mm}$ apart. Stimulation electrodes in M1 were inserted at frontal planes 1.5 and $2.5 \mathrm{~mm}$ rostrally to the bregma, and $1.8 \mathrm{~mm}$ lateral to the midline. Stimulation of this region (intensity, 75-350 $\mu \mathrm{A}$ ) evoked ipsilateral whisker retraction, presumably through activation of the callosal pathway. Electrodes were inserted in S2 at an angle of $45^{\circ}$ from the vertical according to the stereotaxic coordinates of Paxinos and Watson (1998) (frontal planes 2-3 behind the bregma). Cells in that cortical region responded to multiple vibrissae, as assessed by the recording of field potential responses to piezoelectric stimulation. At the end of the experiment, direct current (10 $\mu \mathrm{A} ; 2 \mathrm{~s})$ was passed through the microelectrodes to mark the stimulation site. Rats were perfused with $4 \%$ paraformaldehyde, and histological controls were performed on frontal sections stained for cytochrome oxidase.

Data acquisition and analysis. Once the receptive field of a cell was identified, a peristimulus time histogram (PSTH) (1 ms bin width) was built by collecting 20 responses to cortical stimulation. The magnitude of cortical excitation was estimated as the mean number of spikes per cortical stimulus using a poststimulus time window of $20 \mathrm{~ms}$ after stimulus onset. We did not subtract spontaneous activity when reporting response magnitude because spontaneous activity was always very low $(<1 \mathrm{~Hz})$. The latency of responses was estimated as the bin corresponding to 0.5 of peak value of the PSTH after three bin smoothing with a boxcar kernel.

To detect the presence of inhibitory responses, cells were induced to fire in a sustained manner by juxtacellular application of depolarizing current (1-5 nA), and a PSTH was built by collecting 50-100 responses to cortical stimulation. Collecting such a large number of responses ensures that background activity (counts per bin) was large enough to assess a statistically significant amount of inhibition. We tested for the presence of inhibitory responses by comparing firing rates within a $20 \mathrm{~ms}$ time window after stimulus onset to prestimulus firing rates estimated over a $50 \mathrm{~ms}$ period ( $a=0.025$; one-tailed $t$ test). The poststimulus time window was offset by $25 \mathrm{~ms}$ to accommodate the latency of inhibition. Data analysis was performed with the Neuroexplorer (Plexon), Excel (Microsoft), and $\mathrm{G}^{\star}$ Power 3.0 (freeware) software. Results are reported as mean $\pm \mathrm{SD}$.

Lesion of the caudalis subnucleus. Elimination of the caudalis input to the $\mathrm{SpVi}$ was attempted in six rats by making an electrolytic lesion at the level of the obex. A tungsten electrode (shaft diameter, $200 \mu \mathrm{m}$; tip diameter, $20 \mu \mathrm{m}$, deinsulated over $1 \mathrm{~mm}$ ) was used to pass $1.5 \mathrm{~mA}$ for $2 \mathrm{~s}$ at three depths along two descents. In each lesioned rat, the extent of the lesion was assessed on horizontal sections of the brainstem stained for cytochrome oxidase.

Tract-tracing experiments. Tracer injections were made in three rats under ketamine/xylazine anesthesia. A small amount $(0.2 \mu \mathrm{l})$ of Alexa 555 -conjugated cholera toxin B subunit (CTB) (1\% w/v dissolved in 0.1 м PBS, pH 7.4; Invitrogen) was pressure injected into the SpVic with a micropipette (diameter, $\sim 20 \mu \mathrm{m}$ ). After a survival period of $48 \mathrm{~h}$, the animals were deeply anesthetized and perfused transcardially with $200 \mathrm{ml}$ of PBS followed by $300 \mathrm{ml}$ of $4 \%(\mathrm{w} / \mathrm{v})$ formaldehyde in $0.1 \mathrm{M}$ phosphate buffer, $\mathrm{pH} 7.4$.

In situ hybridization. After fixation, brains were cryoprotected with $30 \%(\mathrm{w} / \mathrm{w})$ sucrose in PBS and cut horizontally at $30 \mu \mathrm{m}$ on a freezing microtome. cDNA fragments corresponding to regions of the vesicular inhibitory amino acid transporter (VIAAT) (a marker of GABAergic and glycinergic neurons) cDNA (866-1817; GenBank accession number NM_009508), the glutamic acid decarboxylase (GAD67) (a marker of GABAergic neurons) cDNA (nucleotides 276-894; GenBank accession number NM_008077), the vesicular glutamate transporter type 1 (VGluT1) (a marker of excitatory neurons) cDNA (855-1788; XM_133432.2), and the vesicular glutamate transporter type 2 (VGluT2) (a marker of excitatory neurons) cDNA (848-2044; NM_080853.2) were cloned into vector pBluescript II SK $(+)$ (Stratagene). With the linearized plasmid as template, sense and antisense single-strand RNA probes were synthesized with a digoxigenin labeling kit (Roche Diagnostics). The procedure for nonradioactive in situ hybridization has been described previously (Liang et al., 2000). Briefly, free-floating sections were washed in phosphate buffer for $5 \mathrm{~min}$, and then acetylated in freshly prepared $0.25 \%$ (v/v) acetic anhydride in $0.1 \mathrm{~m}$ triethanolamine for $10 \mathrm{~min}$ by vigorous shaking. After a rinse with $30 \mathrm{~mm} \mathrm{NaCl}$ and $30 \mathrm{~mm}$ sodium citrate $(2 \times$ SSC), sections were hybridized with $1.0 \mu \mathrm{g} / \mathrm{ml}$ digoxigenin-labeled sense or antisense RNA probes for GAD67, VIAAT, VGluT1, and VGluT2 in a mixture of $50 \%(\mathrm{v} / \mathrm{v})$ formamide, $5 \times \mathrm{SSC}, 2 \%$ blocking reagent (Roche Diagnostics), $0.1 \% \mathrm{~N}$-lauroylsarcosine (NLS), and $0.1 \%$ SDS for $20 \mathrm{~h}$ at $70^{\circ} \mathrm{C}$. After washing twice in $50 \%$ formamide, $2 \times$ SSC, and $0.1 \%$ NLS for $20 \mathrm{~min}$ at $60^{\circ} \mathrm{C}$, sections were incubated with $20 \mathrm{~g} / \mathrm{ml} \mathrm{RNase}$ A for $30 \mathrm{~min}$ at $37^{\circ} \mathrm{C}$, washed twice for $20 \mathrm{~min}$ at $37^{\circ} \mathrm{C}$ in $2 \times$ SSC and $0.1 \%$ NLS, and then in $0.2 \times$ SSC and $0.1 \%$ NLS. Subsequently, sections were incubated with 1:3000-diluted peroxidase-conjugated sheep anti-digoxigenin antibody Fab fragment (Roche Diagnostics), and the signals were amplified with a biotinyl tyramide reagent (Adams, 1992). Then, sections were incubated with Alexa 488-conjugated streptavidin ( $5 \mu \mathrm{g} / \mu \mathrm{l}$; Invitrogen) in PBS containing $0.3 \%$ Triton X-100 for 1 h. Hybridization with the sense probe did not produce any signals. Some sections were stained with cresyl violet or cytochrome oxidase histochemistry.

Cell count. Horizontal sections through the ventral region of the subnucleus caudalis $(\mathrm{SpVc})$ and $\mathrm{PrV}$ were used for counting tracer- and mRNA-positive neurons. The number of retrogradely labeled cells in sections processed for in situ hybridization was estimated under confocal microscopy with a $40 \times$ objective (Pascal; Zeiss). Approximately 12 adjacent fields $(230 \times 230 \mu \mathrm{m})$ were scanned in a grid-like manner across the SpVc in each section. For each field, a stack of 20 optical slices was acquired, and counts were made from the stacked images.

\section{Results}

Previous studies have provided clear anatomical and electrophysiological evidence that projection cells in the SpVi respond to 
A

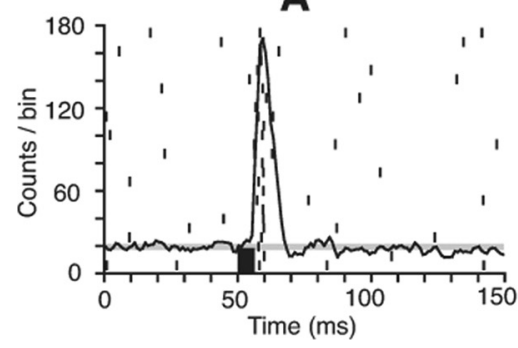

B

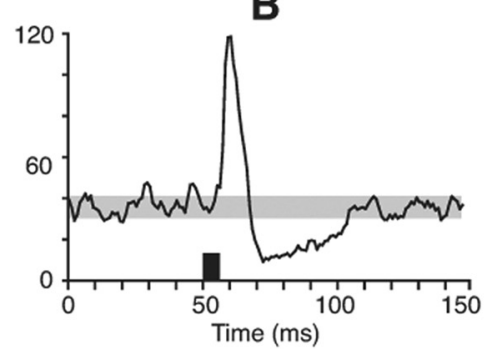

C

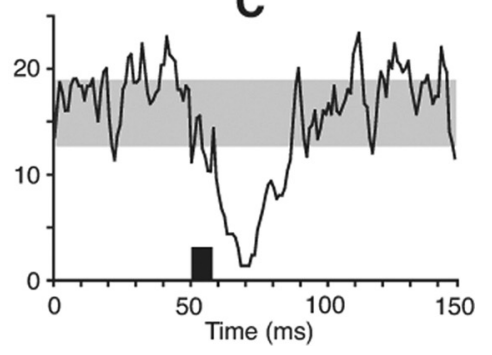

Figure 1. Response of SpVineurons to stimulation of corticofugal pathways. A, Population PSTH of 10 multiwhisker cells whose receptive field included the vibrissa represented in the stimulated barrel column. The stimulus train (black bar) evoked excitation but no significant inhibition. The gray area in all PSTHs indicates the mean number of counts per bin \pm 1 1SD in a prestimulus time window of $50 \mathrm{~ms}$. The raster in $\boldsymbol{A}$ displays background and evoked discharges in one of the units. B, Population PSTH of 23 multiwhisker cells after stimulation of the vibrissa motor cortex. Note the presence of inhibition after the initial excitation. C, Monowhisker cells are inhibited by motor cortex stimulation (population PSTH of 11 units). Note that all population PSTHs were built from cells whose background discharges were driven by current injection.

multiple vibrissae, whereas nonprojection cells or cells positively identified as intersubnuclear-projecting neurons respond to a single vibrissa (Woolston et al., 1983; Jacquin et al., 1986, 1989a,b). Thus, hereinafter we shall consider multiwhisker cells as projection neurons and monowhisker cells as intersubnuclearprojecting interneurons. Supplemental Figure S1 (available at www.jneurosci.org as supplemental material) shows representative recordings of whisker-evoked responses in projection cells and interneurons.

\section{Stimulation of a barrel column}

We examined the effect of microstimulation of a single barrel column on the activity of 111 vibrissa-sensitive neurons in the rostral and caudal sectors of the SpVi. Sixty-one of these neurons had multiple-vibrissa receptive field and the remaining 50 responded to a single vibrissa. Most of the latter neurons were recorded in the SpVic.

The receptive field of 38 projection cells included the vibrissa represented in the stimulated barrel column and, as a rule, these cells were activated by cortical stimulation ( $n=37$ units) (i.e., $97 \%$ ). Responses consisted of one to two action potentials (on average, $1.3 \pm 0.6$ spikes per stimulus train) occurring at a mean latency of $9.7 \pm 0.8 \mathrm{~ms}$ (Fig. 1A). Conversely, none of the projection cells whose receptive field did not include the vibrissa represented in the stimulated barrel column $(n=23)$ was excited by cortical stimulation. Regardless of the vibrissa to which interneurons responded, none of these units $(n=50)$ was driven by cortical stimulation.

We also examined whether stimulation of a barrel column inhibited interpolaris cells. This test was performed in a subset of monowhisker and multiwhisker cells (8 monowhisker cells and 12 multiwhisker cells) by assessing the amount of suppression of background discharges produced by cortical stimulation. Regardless of the size and topography of receptive field, no significant inhibition was observed in any of the cells at low stimulation intensity $(15-50 \mu \mathrm{A})$. At higher intensities (up to $200 \mu \mathrm{A}$ ), a short-lasting depression (i.e., 20-30 ms) of background discharges was observed in $30 \%$ of these cells, but inhibition was generally weak and unrelated to the topography of the receptive fields. Because we were unable to disclose inhibition at stimulation intensities that currently induced excitatory responses, these inhibitory effects might have resulted from current diffusion to surrounding barrels or septa (but see below).

In sum, corticofugal cells in a given barrel column excite exclusively projection cells whose receptive field includes the corresponding vibrissa, but this barrel-specific output exerts no direct excitatory action on intersubnuclear-projecting interneurons. We thus examined the possibility that latter cells receive cortical drive from the dysgranular zone of S1 or from S2.

\section{Stimulation of the motor cortex}

The dysgranular zone of S1 consists of interbarrel regions and regions in the immediate surrounding of the barrel field. Thus, focal electrical stimulation at any site in S1 is bound to activate only a small fraction of the corticotrigeminal cells in the dysgranular cortex. To maximize the recruitment of these cells, we stimulated the vibrissa motor cortex. Tract-tracing studies already demonstrated reciprocal connections between the dysgranular zone of $\mathrm{S} 1$ and the vibrissa motor cortex (Veinante and Deschênes, 2003; Chakrabarti and Alloway, 2006), and it was also shown that activation of $\mathrm{S} 1$ via these corticocortical projections produces excitatory and inhibitory effects in the SpVi (Urbain and Deschênes, 2007). We thus used electrical stimulation of the vibrissa motor cortex to determine how bulk activation of corticotrigeminal cells in the dysgranular zone (and perhaps those in the granular zone as well) affect SpVi neurons.

The effect of motor cortex stimulation was tested on 34 projection cells and 14 interneurons in three rats. These neurons were driven by juxtacellular current injection to detect subthreshold excitation and assess the presence of inhibition. Fortyseven percent of the projection cells $(n=16)$ were excited by motor cortex stimulation (Fig. $1 B$ ) (response magnitude, $1.60 \pm$ 0.66 spikes per stimulus train) at a mean latency of $10.95 \pm 1.65$ ms; yet none of the 14 interneurons was excited by motor cortex stimulation (Fig. 1C).

Motor cortex stimulation produced significant inhibition ( $\alpha=0.025$; one-tailed $t$ test) in $62 \%$ of the projection cells and $79 \%$ of interneurons (Fig. $1 B, C$ ). In population PSTH that included responses of both populations of cells, the amount of inhibition reached $59.44 \pm 7.77 \%$ with respect to prestimulus firing probability.

\section{Stimulation of S2}

The above experiments showed that none of the SpVi interneurons was activated by $\mathrm{S} 1$ or motor cortex stimulation. The vast majority of these interneurons are located in the caudal sector of the nucleus (Furuta et al., 2008), which also contains projection cells that give rise to a pathway that terminates principally in S2 (Pierret et al., 2000; Bokor et al., 2008). We thus examined whether S2 provides direct input to monowhisker cells in the SpVic. Stimulation of S2 (Fig. 2) excited 14 of the 25 multiwhisker cells tested ( $56 \%$; on average, $1.24 \pm 0.74$ spike per stimulus) 


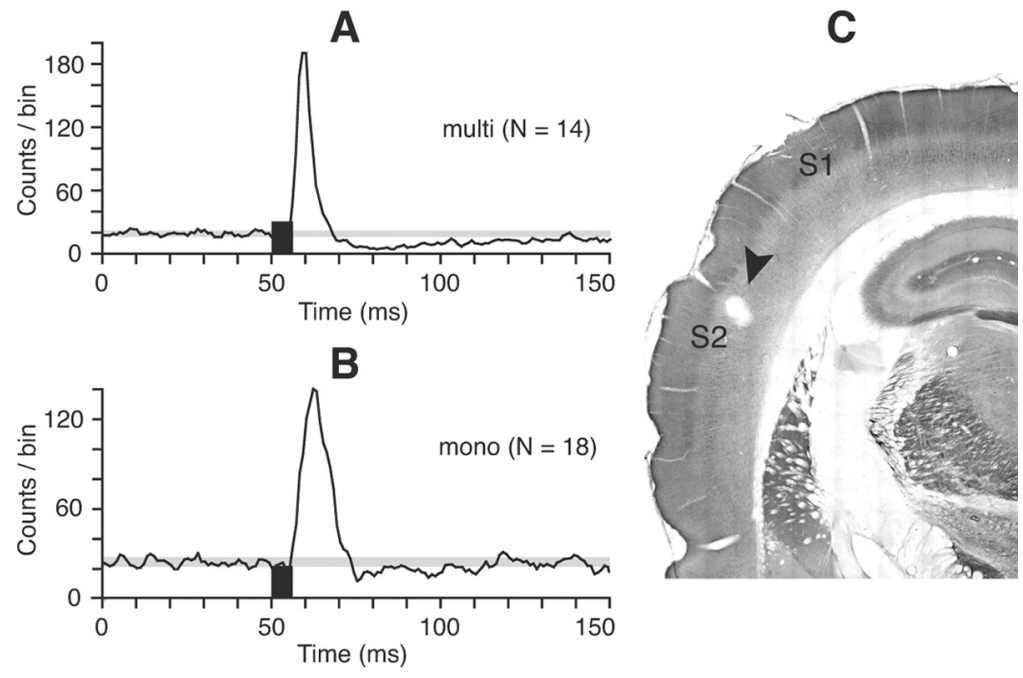

Figure 2. Effect of S2 stimulation on SpVineurons. S2 stimulation (black bar) excites both multiwhisker $(\boldsymbol{A})$ and monowhisker $(\boldsymbol{B})$ cells. Shown are population PSTHs of 14 units in $\boldsymbol{A}$ and 18 units in $\boldsymbol{B}$. The gray area in PSTHs indicates the mean number of counts per bin \pm 1 1SD in a prestimulus time window of $50 \mathrm{~ms}$. The frontal section in ( shows the location of the stimulating electrode in $\mathrm{S2}$ (arrowhead).

at a mean onset latency of $9.55 \pm 1.32 \mathrm{~ms}$. Eighteen of the 33 monowhisker cells tested (55\%) were also driven by S2 stimulation (on average, $1.36 \pm 0.66$ spike per stimulus) at a mean latency of $9.35 \pm 1.88 \mathrm{~ms}$. These results clearly indicate that corticotrigeminal cells in S2, but not those in S1, contact intersubnuclear-projecting interneurons in the SpVic.

Stimulation of S2 produced significant inhibition $(\alpha=0.025$; one-tailed $t$ test) in $93 \%$ of the projection cells tested $(n=14)$ and $50 \%$ of interneurons $(n=18)$. At population level (Fig. $2 A, B$ ), the amount of inhibition was statistically significant in projection cells ( $t$ test; $p=0.004)$, but not in interneurons ( $t$ test; $p=0.272$ ). This is because in $33 \%$ of the interneurons firing rate increased instead of decreasing in the poststimulus time window used to measure inhibition (25-45 ms after stimulus onset) (see Materials and Methods).

\section{Origin of inhibition: retrograde labeling and in situ hybridization}

The fact that none of the putative inhibitory interneurons in the $\mathrm{SpVi}$ was activated by $\mathrm{S} 1$ or motor cortex stimulation raised the issue of the origin of cortically driven inhibition in the SpVi. No anatomical study has yet reported inhibitory input to the SpVi that arises from outside the brainstem trigeminal complex. The other trigeminal subnuclei, however, receive corticofugal input, and the caudalis subnucleus $(\mathrm{SpVc})$ is the one that innervates most densely the SpVi (Jacquin et al., 1990a). We thus combined retrograde labeling with in situ hybridization to determine the nature of caudalis projections to the interpolaris. These experiments revealed that relatively few caudalis cells expressing VGluT1 (8\%; 79 of 1001) or GAD67 (12\%; 107 of 873) transcripts projected to the SpVi, whereas $28 \%$ of the cells (282 of 995) were VIAAT-positive, and 67\% (640 of 949) expressed the VGluT2 transcript (Fig. 3). One should note that injection sites only involved part of the SpVi, so that these figures likely underestimate the actual proportion of caudalis cells that project to the SpVi. Thus, these anatomical data provide direct evidence that a sizeable proportion $(\sim 30 \%)$ of caudalis cells that project to the SpVi use either GABA or glycine as inhibitory transmitter.

In contrast with the $\mathrm{SpVc}$, the $\mathrm{PrV}$ contained very few retrogradely labeled VIAAT-positive cells ( $0-3$ cells per section) (supple- mental Fig. S2, available at www.jneurosci. org as supplemental material). This result accords with the immunohistochemical study by Avendaño et al. (2005), who found the densest concentration of GABA and glycine immunoreactive cells in the SpVc and $\mathrm{SpVi}$, whereas the PrV contained the least.

Origin of inhibition: lesion of the SpVc We next examined whether motor cortexinduced inhibition in the SpVi persisted after lesion of the caudalis subnucleus. The SpVc lies right next to the SpVic, and the border between the two subnuclei adopts an oblique orientation with respect to the dorsoventral and mediolateral axis of the brainstem. Thus, lesioning the $\mathrm{SpV} c$ without encroaching on the SpVic is practically impossible. Here, we shall focus on results obtained in two rats in which the lesion, although incomplete, severed a sizeable portion of the rostral SpVc (Fig. 4D). We recorded 35 projection cells and 7 interneurons in these two rats. As in normal rats, $48 \%$ of the projection cells were excited by motor cortex stimulation, with response magnitude similar to that observed in normal rats (Fig. 4A) (1.20 \pm 0.53 spikes per stimulus train). However, the proportion of projection cells that demonstrated a significant amount of inhibition fell to $28 \%$ (as opposed to $62 \%$ in normal rats). Likewise, none of the interneurons was excited by motor cortex stimulation, and inhibition was observed in only two of the seven cells tested (29\% as opposed to $79 \%$ in normal rats). Again, in population PSTH that included responses of projection cells and interneurons, the amount of inhibition reached $21.47 \pm 8.25 \%$ with respect to prestimulus firing probability (59.44 $\pm 7.77 \%$ in normal rats) (Fig. $4 C$, histograms). Although the amount of inhibition was statistically significant in both normal and lesioned rats ( $t$ test; $p<0.0001$ and $p=0.0316$, respectively), the difference in the amount of inhibition between the two groups was also significant $[t$ test; $p=0.0013$; power $(1-$ $\beta)=0.953$. Thus, lesion of the SpVc, albeit incomplete, produced a marked reduction in the amount of inhibition evoked by motor cortex stimulation. In sum, results in SpVc-lesioned rats fully accord with the anatomical data, indicating that cortically induced inhibition in the SpVi is mediated principally by SpVc inhibitory neurons that receive input from the dysgranular zone of S1.

\section{Discussion}

The main finding of the present study is that cortical areas S1 and S2 exert a differential control over the excitability of projection cells and interneurons in the SpVi. It was previously shown that inhibitory interneurons in the SpVi project to the PrV (Furuta et al., 2008). The demonstration that these interneurons are themselves inhibited by inhibitory inputs from the $\mathrm{SpVc}$ provides a circuit for a mechanism of disinhibition through which the cerebral cortex can control the relay of sensory messages in the lemniscal pathway.

\section{Methodological considerations}

A common difficulty with activation of cortical neurons by electrical stimulation is to determine to what extent observed effects result from current spread and transsynaptic activation. Studies 
that examined this issue agree on the fact that stimulation preferentially activates the largest and most excitable elements of cortex directly, that is, by and large the axons of the pyramidal cells (Stoney et al., 1968; Swadlow, 1992; Nowak and Bullier, 1998; Tehovnik et al., 2006; Histed et al., 2009). Antidromic invasion of neurons whose axon collaterals pass by the stimulation site and intracortical transsynaptic activation produce comparatively smaller effects because axon collaterals are less excitable, and lateral connections within cortex generally induce small amplitude synaptic potentials. Moreover, neurons activated directly make a more significant contribution to the evoked response because they are synchronously activated compared with the neurons activated transsynaptically. Given the demonstrated anatomical connections between cortex and trigeminal nuclei, one would expect the earliest responses to be induced by the activation of these direct connections. The SDs of mean latencies $(9.7 \pm$ $0.8 \mathrm{~ms}$ from a barrel column; $10.95 \pm 1.65$ $\mathrm{ms}$ from motor cortex; and $9.55 \pm 1.32$ $\mathrm{ms}$ from S2) are rather small, which indicates that the contribution of disynaptic or multisynaptic inputs is likely minimal.

Stimulation of a barrel column was shown to excite only multiwhisker cells whose receptive field contained the vibrissa represented in that barrel column. This is congruent with the fact that corticotrigeminal axons from a given barrel column innervate only the corresponding barrelette in brainstem (Welker et al., 1988). If current had spread to adjacent barrel columns, some SpVi cells should have been excited even though their receptive field did not include the vibrissa represented in the stimulated column. At current intensity used in the present study, this was never observed. Thus, the consistency and selectivity of the corticofugal effects support the conclusion that the excitation of SpVi neurons preferentially resulted from the activation of a single barrel column.

The vibrissa motor cortex, S1, and S2 are linked by corticocortical connections (Fabri and Burton, 1991; Chakrabarti and Alloway, 2006), which raises the issue of the origin of responses evoked in the SpVi by electrical stimulation of these cortical areas. Corticofugal cells in M1 do not project to the sensory trigeminal nuclei (Miyashita et al., 1994), and it was previously shown that the effects of M1 stimulation on SpVi neurons are eliminated after lesion of both S1 and S2 (Urbain and Deschênes, 2007). Corticocortical projections from M1 to S1 are highly divergent, a small deposit of biotinylated dextran in M1 resulting in the anterograde labeling of terminal fields across multiple septal columns in S1 (Veinante and Deschênes, 2003). Therefore, M1 stimulation ought to activate trigeminal cells via these corticocortical projections. This is reminiscent of spinal cord dorsal root potentials elicited by motor cortex stimulation in cats, which are abolished by lesion of the somatosensory areas (Andersen et al., 1964).

Area S2 has strong projections to S1, so that the excitation of multiwhisker SpVi cells by S2 stimulation might have resulted, at least in part, from synaptic activation of corticofugal cells in S1. Although we cannot exclude this possibility, the key issue about S2 (and this why S2 was stimulated), is that it is the only area from which monowhisker cells could be excited.

\section{Comparison with a previous study}

Woolston et al. (1983) reported the first piece of evidence for a differential effect of corticofugal activity on interpolaris cells. 

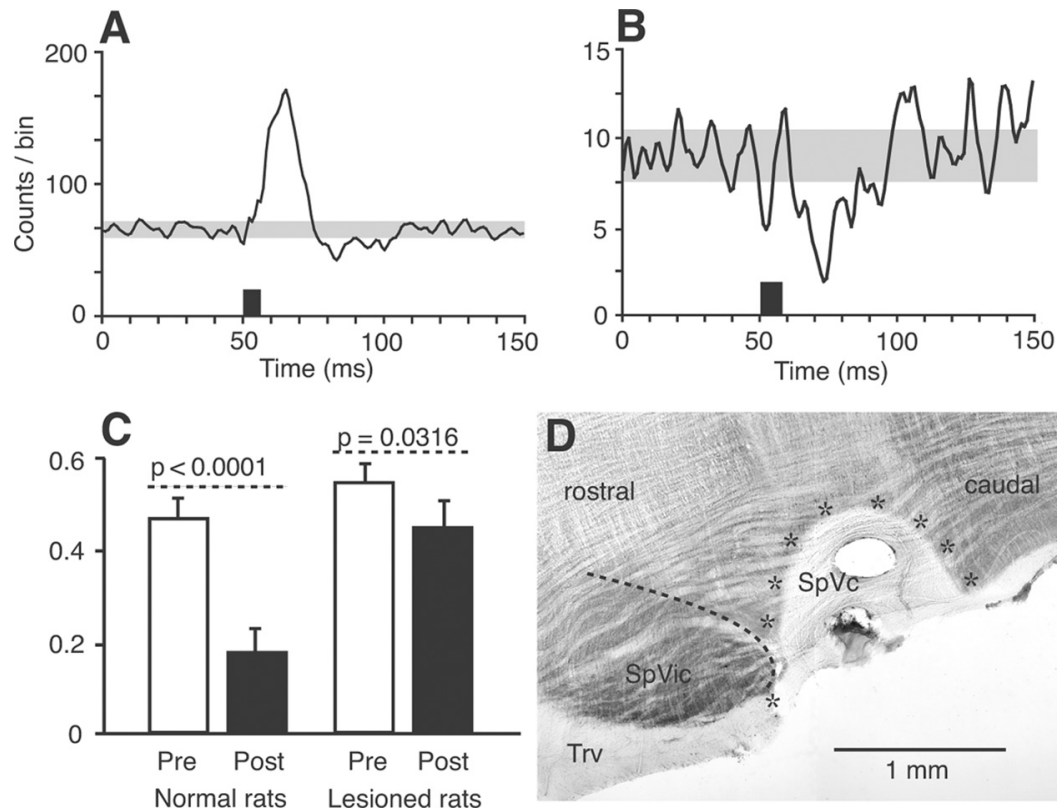

Figure 4. Lesion of the SpVc significantly depresses the inhibitory response induced by motor cortex stimulation in the SpVi. Motor cortex-induced excitation persists after the lesion, but inhibition is markedly reduced (population PSTH of 35 multiwhisker units in $A$; compare with PSTH in Fig. $1 B$ ). The amount of inhibition is also reduced in monowhisker cells (population PSTH of 7 units in $\boldsymbol{B}$ ). Histograms in ( show the decrease in firing probability within a poststimulus time window of $20 \mathrm{~ms}$ (Post; $25-45 \mathrm{~ms}$ after the onset of cortical stimulation; black bars) with respect to firing probability in a prestimulus time window of $50 \mathrm{~ms}$ (Pre; white bars). Although the amount of inhibition was statistically significant in both normal and lesioned rats ( 59.44 and $21.47 \%$, respectively), it was markedly decreased after lesion of the SpVc. Error bars indicate \pm 1 SD. The horizontal section of the brainstem in D shows the extent of an SpVc lesion (area surrounded by stars). The dashed line outlines the border between the SpVi and SpVc. Trv, Trigeminal tract.

They showed that stimulation of a barrel column excited exclusively multiwhisker cells whose receptive field included the whisker represented in the stimulated barrel column and that monowhisker cells were much less likely to be affected by S1 stimulation. Our study fully confirms those results and further shows that local circuit cells receive their cortical drive from S2, not $\mathrm{S} 1$, and that the projection of $\mathrm{S} 1$ to the caudalis subnucleus recruits intersubnuclear-projecting cells that inhibit both projection cells and interneurons in the SpVi.

At odd with the results of Woolston et al. (1983), barrel column stimulation did not inhibit cells whose receptive field did not include the vibrissa represented in the stimulated barrel. However, most of the receptive fields at the cortical stimulation sites in that study contained two whiskers and current intensities of up to $100 \mu \mathrm{A}$ were used, suggesting that inhibition might have been recruited by the activation of corticotrigeminal cells in septal columns. This possibility is supported by the fact that bulk activation of these columns by motor cortex stimulation produces both excitation and inhibition in the SpVi.

\section{Anatomical basis of cortical input specificity}

The selective excitation of multiwhisker cells whose receptive field included the vibrissa represented in the stimulated barrel column is fully congruent with the anatomical organization of the projection of the barrel column in the SpVi. Just like terminals of first-order vibrissal afferents, those given off by barrelassociated corticotrigeminal cells are spatially ordered, with each barrel column projecting to a corresponding barrelette in brainstem (Hayashi, 1980; Jacquin et al., 1986; Welker et al., 1988; Henderson and Jacquin, 1995). Thus, both the vibrissal receptive field of a neuron and the barrel-specific excitatory drive it receives are primarily determined by the way dendrites cut across the array of barrelettes. A notable exception to this rule is the absence of cortical excitation in monowhisker cells, which is the more remarkable as bulk activation of $\mathrm{S} 1$ by motor cortex stimulation also failed to activate any of these neurons. This is clear indication that intersubnuclear interneurons in the SpVi do not receive direct drive from layer 5 cells in S1, which points to a high specificity of connections between cells in cortex and trigeminal nuclei. The topography of corticofugal projections from septal columns and S2 across the array of barrelettes and intervening septa is currently unknown. Yet intersubnuclear projecting axons give off arrays of terminals that lie parallel to, or in register with, the barrelettes (Jacquin et al., 1990a; Timofeeva et al., 2004), which should enable inhibition and disinhibition to be expressed with a high degree of topographic specificity.

An interesting observation in two previous anatomical studies of corticobrainstem projections is that many of the collaterals that terminate in the SpVi derived from corticofugal axons that ascended through the medulla after crossing at the level of the pyramidal decussation (Welker et al., 1988; Jacquin et al., 1990b). This observation nicely fits with our results, in that it suggests that corticofugal axons branch in the SpVc before terminating in the SpVi.

\section{Central control of brainstem circuits: mechanism and functional significance}

The suppression of background discharges induced by current injection is clear indication that corticofugal inhibition is mediated postsynaptically. Yet a number of studies have shown that corticofugal volleys produce presynaptic inhibition of cutaneous and pain inputs in the spinal cord and caudal trigeminal subnucleus (Andersen et al., 1964; Hammer et al., 1966; Abdelmoumène et al., 1970) (for review, see Rudomin, 2009). Ultrastructural studies have also revealed the presence of axoaxonic GABAergic contacts on primary afferent terminals in trigeminal sensory nuclei (Bae et al., 2000). Whether corticofugal axons also exert their effect on vibrissal inputs by a mechanism of presynaptic inhibition would deserve additional investigation.

Several studies in freely moving or head-restrained rodents have reported that vibrissal responses in barrel cortex are markedly depressed when stimuli are delivered during periods of free whisking compared with periods of quiet wakefulness (Fanselow and Nicolelis, 1999; Crochet and Petersen, 2006; Ferezou et al., 2006; Hentschke et al., 2006; Lee et al., 2008). In contrast, responses recover in magnitude when the animal actively makes whisker contact with an object, which suggests the existence of subcortical mechanisms that gate the flow of sensory inputs during different types of motor activity. This raises the question of where and how gating occurs. Because a reduction in response magnitude is also observed in VPM during free whisking 
(Fanselow and Nicolelis, 1999), the inhibitory gating of vibrissal inputs likely occurs in $\mathrm{PrV}$. This possibility is supported by the fact that input suppression during free whisking is attenuated after pharmacological silencing inhibitory projections from the SpVic to the PrV (Lee et al., 2008). What the present results further suggest is that the activity of SpVic inhibitory cells is itself under the control of S2 and of SpVc interneurons that are activated by corticofugal axons. This chain of inhibitory connections $(\mathrm{SpVc} \rightarrow \mathrm{SpVi} \rightarrow \mathrm{PrV})$ provides an anatomical basis for a mechanism of disinhibition through which the cerebral cortex can control the flow of vibrissal messages in the lemniscal pathway.

\section{References}

Abdelmoumène M, Besson JM, Aléonard P (1970) Cortical areas exerting presynaptic inhibitory action on the spinal cord in cat and monkey. Brain Res 20:327-329.

Adams JC (1992) Biotin amplification of biotin and horseradish peroxidase signals in histochemical stains. J Histochem Cytochem 40:1457-1463.

Andersen P, Eccles JC, Sears TA (1964) Cortically evoked depolarization of primary afferent fibers in the spinal cord. J Neurophysiol 27:63-77.

Avendaño C, Machín R, Bermejo PE, Lagares A (2005) Neuron numbers in the sensory trigeminal nuclei of the rat: a GABA- and glycine-immunocytochemical and stereological analysis. J Comp Neurol 493:538-553.

Bae YC, Ihn HJ, Park MJ, Ottersen OP, Moritani M, Yoshida A, Shigenaga YJ (2000) Identification of signal substances in synapses made between primary afferents and their associated axon terminals in the rat trigeminal sensory nuclei. J Comp Neurol 418:299-309.

Bokor H, Acsády L, Deschênes M (2008) Vibrissal responses of thalamic cells that project to the septal columns of the barrel cortex and to the second somatosensory area. J Neurosci 28:5169-5177.

Chakrabarti S, Alloway KD (2006) Differential origin of projections from SI barrel cortex to the whisker representations in SII and MI. J Comp Neurol 498:624-636.

Crochet S, Petersen CC (2006) Correlating whisker behavior with membrane potential in barrel cortex of awake mice. Nat Neurosci 5:608-610.

Fabri M, Burton H (1991) Ipsilateral cortical connections of primary somatic sensory cortex in rats. J Comp Neurol 311:405-424.

Fanselow EE, Nicolelis MA (1999) Behavioral modulation of tactile responses in the rat somatosensory system. J Neurosci 19:7603-7616.

Ferezou I, Bolea S, Petersen CC (2006) Visualizing the cortical representation of whisker touch: voltage-sensitive dye imaging in freely moving mice. Neuron 50:617-629.

Friedberg MH, Lee SM, Ebner FF (1999) Modulation of receptive field properties of thalamic somatosensory neurons by the depth of anesthesia. J Neurophysiol 81:2243-2252.

Furuta T, Timofeeva E, Nakamura K, Okamoto-Furuta K, Togo M, Kaneko T, Deschênes M (2008) Inhibitory gating of vibrissal inputs in the brainstem. J Neurosci 28:1789-1797.

Hallas BH, Jacquin MF (1990) Structure-function relationships in rat brain stem subnucleus interpolaris. IX. Inputs from subnucleus caudalis. J Neurophysiol 64:28-45.

Hammer B, Tarnecki R, Vyklicky L, Wiesendanger M (1966) Corticofungal control of presynaptic inhibition in the spinal trigeminal complex of the cat. Brain Res 1:216-218.

Hayashi H (1980) Distributions of vibrissae afferent fibers collaterals in the trigeminal nuclei as revealed by intra-axonal injection of horseradish peroxidase. Brain Res 183:442-446.

Henderson TA, Jacquin MF (1995) What makes subcortical barrels? In: Cerebral cortex, the barrel cortex of rodents, Vol 12 (Jones EG, Diamond IT, eds), pp 123-187. New York: Plenum.

Hentschke H, Haiss F, Schwarz C (2006) Central signals rapidly switch tactile processing in rat barrel cortex during whisker movements. Cereb Cortex 16:1142-1156.

Histed MH, Bonin V, Reid RC (2009) Direct activation of sparse, distributed populations of cortical neurons by electrical microstimulation. Neuron 63:508-522.
Jacquin MF, Mooney RD, Rhoades RW (1986) Morphology, response properties, and collateral projections of trigeminothalamic neurons in brainstem subnucleus interpolaris of rat. Exp Brain Res 61:457-468.

Jacquin MF, Golden J, Rhoades RW (1989a) Structure-function relationships in rat brainstem subnucleus interpolaris: III. Local circuit neurons. J Comp Neurol 282:24-44.

Jacquin MF, Barcia M, Rhoades RW (1989b) Structure-function relationships in rat brainstem subnucleus interpolaris: IV. Projection neurons. J Comp Neurol 282:45-62.

Jacquin MF, Chiaia NL, Haring JH, Rhoades RW (1990a) Intersubnuclear connections within the rat trigeminal brainstem complex. Somatosens Mot Res 7:399-420.

Jacquin MF, Wiegand MR, Renehan WE (1990b) Structure-function relationships in rat brain stem subnucleus interpolaris. VIII. Cortical inputs. J Neurophysiol 64:3-27.

Killackey HP, Koralek KA, Chiaia NL, Rhodes RW (1989) Laminar and areal differences in the origin of the subcortical projection neurons of the rat somatosensory cortex. J Comp Neurol 282:428-445.

Lee S, Carvell GE, Simons DJ (2008) Motor modulation of afferent somatosensory circuits. Nat Neurosci 11:1430-1438.

Liang F, Hatanaka Y, Saito H, Yamamori T, Hashikawa T (2000) Differential expression of gamma-aminobutyric acid type B receptor- $1 \mathrm{a}$ and $-1 \mathrm{~b}$ mRNA variants in GABA and non-GABAergic neurons of the rat brain. J Comp Neurol 416:475-495.

Miyashita E, Keller A, Asanuma H (1994) Input-output organization of the rat vibrissal motor cortex. Exp Brain Res 99:223-232.

Nowak LG, Bullier J (1998) Axons, but not cell bodies, are activated by electrical stimulation in cortical gray matter. I. Evidence from chronaxie measurements. Exp Brain Res 118:477-488.

Paxinos G, Watson W (1998) The rat brain in stereotaxic coordinates, Ed 4. London: Academic

Pierret T, Lavallée P, Deschênes M (2000) Parallel streams for the relay of vibrissal information through thalamic barreloids. J Neurosci 20:74557462.

Rudomin P (2009) In search of lost presynaptic inhibition. Exp Brain Res 196:139-151.

Stoney SD Jr, Thompson WD, Asanuma H (1968) Excitation of pyramidal tract cells by intracortical microstimulation: effective extent of stimulating current. J Neurophysiol 31:659-669.

Swadlow HA (1992) Monitoring the excitability of neocortical efferent neurons to direct activation by extracellular current pulses. J Neurophysiol 68:605-619.

Tehovnik EJ, Tolias AS, Sultan F, Slocum WM, Logothetis NK (2006) Direct and indirect activation of cortical neurons by electrical microstimulation. J Neurophysiol 96:512-521.

Timofeeva E, Lavallée P, Arsenault D, Deschênes M (2004) Synthesis of multiwhisker receptive fields in subcortical stations of the vibrissa system. J Neurophysiol 91:1510-1515.

Timofeeva E, Dufresne C, Sík A, Zhang ZW, Deschênes M (2005) Cholinergic modulation of vibrissal receptive fields in trigeminal nuclei. J Neurosci 25:9135-9143.

Urbain N, Deschênes M (2007) Motor cortex gates vibrissal responses in a thalamocortical projection pathway. Neuron 56:714-725.

Veinante P, Deschênes M (2003) Single-cell study of motor cortex projections to the barrel field in rats. J Comp Neurol 464:98-103.

Welker E, Hoogland PV, Van der Loos H (1988) Organization of feedback and feedforward projections of the barrel cortex: a PHA-L study in the mouse. Exp Brain Res 73:411-435.

Wise SP, Jones EG (1977) Cells of origin and terminal distribution of descending projections of the rat somatic sensory cortex. J Comp Neurol 175:129-157.

Wise SP, Murray EA, Coulter JD (1979) Somatotopic organization of corticospinal and corticotregiminal neurons in the rat. Neuroscience 4:65-78.

Woolston DC, La Londe JR, Gibson JM (1983) Corticofugal influences in the rat on responses of neurons in the trigeminal nucleus interpolaris to mechanical stimulation. Neurosci Lett 36:43-48. 